for months at a time without producing any symptoms of iodism. The two cases I have treated tolerated the drug well. The first case in five months took 16,320 grains, or an average of 103 grains daily, without exhibiting any undue symptoms ; indeed, the patient appeared to improve while taking the iodide and expressed herself as feeling much brighter than formerly. She missed the drug when it was omitted. The second patient took for over 14 months an average of 40 grains per day and improved from the commencement of its administration. He has developed bone and weight and is now a strong, healthy youth.

Jackson's-lane, $\mathrm{N}$.

\section{DENTAL DISEASE AND THE MEDICAL PROFESSION.}

BY R. DENISON PEDLEY, F.R.C.S. EDIN., L.D.S.

THE object of this paper is to direct attention to certain facts which are well worthy of consideration by medical men. It has long been evident that dental diseases are swidely prevalent among all classes of the community. "Their effects are far-reaching-from infancy to old age-not so much in destroying life as in marring it. By interfering with nutrition, poisoning the system, and generally lowering the vitality of the body they pave the way to many other diseases. Truly an important factor in physical deterioration. If this be true-and few will gainsay it-it is a matter of sufficient importance for the medical profession as a whole to take an active interest in supporting remedial and preventive measures as they have done in the past and are doing to-day for other diseases. Excluding, of necessity, the dental specialist and a few enlightened physicians and surgeons, the attitude of the medical profession toward dental diseases in their midst has hitherto been one of indifference. Why should this be? The answer is simple. Medical practitioners, as a rule, know very little about dental diseases. How should they? Let us take London as typical of what prevails throughout the United Kingdom. In most of the hospitals where medical students receive their training one or more dental surgeons are appointed. As a rule, a course of lectures on dental surgery is delivered either in the summer or the winter sessions and demonstrations are given in the dental department. To either of these medical students may attend or not as they please. The subject is optional. It is true that in the out-patient department the student will often have the opportunity of extracting an acling tooth or one which is causing an alveolar abscess, but he does not know that an examination of the mouth with mirror and probe will reveal defective teeth which on casual inspection escape observation, nor is he aware of the fact that pain is but one symptom of dental disease and that not the most amportant. Though half the patients he attends to -at a low estimate-will have carious teeth, seldom is it pointed out that necrotic roots must no more be permitted than necrotic bone in any other part of the body. Not often will it be insisted that septic material from the teeth and the tissues which surround them is spoiling the patient's digestion and may lead to infection of glands or of the blood itself.

When the student enters the wards he has been taught to make a careful examination of the patient's body. The condition of the various organs and the symptoms observed are all carefully entered in the clinical notes. The condition of the patient's mouth and the number of carious teeth are generally ignured, unless the patient is suffering from pain or swelling, and this notwithstanding the fact that more than half the patients will be affected with oral sepsis in one form or another. If it be a children's ward, four-fifths of the patients will have carious teeth. Walk round the wards of the hospitals with the physicians and surgeons, and how many will ask their clerks or dressers, their house physicians or house surgeons, whether a patient's mouth has been examined, and if not the reason why? How many will insist that the patient's mouth must in every case be careEully examined and a note made of the condition of the teeth and the mucous membrane around them? Without a healthy mouth the patient can scarcely have a healthy body There are exceptions, but as a rule the subject is jgnored. Yet it will be admitted that apart from any special treatenent, such as an operation or the administration of certain drugs, the surgeon and the physician are alike in that they rely for the recovery of the patient upon careful nursing, perfect cleanliness, fresh air, nutritious food, and the removal of all sources of irritation. The purest air will be tainted when it passes through a mouth loaded with patbogenic bacteria. Every carious tooth is a cup containing its quantum of septic material which when churned up in mastication will taint the most nutritious food, and defective teeth are thus a constant source of irritation.

Step into the ideal operating theatre, with its germ-proof walls and floor. The nurses are spotlessly clean. The surgeon, the assistants, and the anæsthetist are all clad in aseptic garments, with caps to match. The hands of the operator and his assistants are carefully cleansed and are often clad in rubber gloves. Every instrument is sterilised; every dressing is rendered aseptic. That part of the patient's body to be operated upon is scrupulously cleansed, but among that small group around the patient it would be difficult to find one sterilised mouth.

Turn to the text-books on medicine and surgery, examine them carefully, and seldom will you find any reference to carious teeth or oral sepsis as an important factor in the production of disease. Neither in one nor the otber is mention made of the fact that an examination of the patient's teeth is a matter of urgent necessity. Of course there are books where the dental surgeon has written a special chapter, but it will not have the weight or authority to the medical student as if written by the physician or surgeon himself. If you ask a medical student why he does not attend the dental department, or read a special textbook on dental surgery, or attend a course of lectures on dental surgery, he will tell you frankly that he is not going in for dentistry. Most of the students trained in the London hospitals take the Membership of the Royal College of Surgeons of England and the Licentiateship of the Royal College of Physicians of London. Many later take the higher qualifications of Fellow or Member of these colleges respectively. A large number pass through the portals of the University of London and take the qualifications of Bachelor of Medicine and Bachelor of Surgery, and, finally, Doctor of Medicine and Master of Surgery. So thorough are these examinations that the students of one hospital are examined by the teachers of other hospitals, never by their own. Look carefully over the papers set for the final examinations in any or all of these diplomas during the past ten years: and you will not find a single question upon dental caries. In the papers for the Membership of the Royal College of Surgeons of England there is occasionally a question on the symptoms, treatment, and diagnosis of abscess of the antrum. In the papers for the Licentiateship of the Royal College of Physicians of London there is occasionally one on facial neuralgia. In the papers for the Fellowship of the Royal College of Surgeons of 1897 there is one question on submaxillary cellulitisangina Ludovici. In the papers for the B.S. of the University of London in 1900 there is one question on necrosis of the jaw; in 1896 there is one on abscess of the antrum. In the surgery papers of the M.B. in 1894 one purely dental question is to be found on the origin, symptoms, diagnosis, and treatment of follicular odontome or dentigerous cyst.

The reply to these statements by the physician and surgeon is readily given. "The medical student is overburdened already. Would you have us add another subject and thus increase bis burden?" Such an answer would be incontrovertible if it were desired that the medical student should have a training in dental surgery and all that this involves. The whole object of his training is for the cure and prevention of disease. Who deplores the ignorance of the lay public upon questions of health more than the medical profession? Is it not then an anomaly that hundreds of young practitioners should emerge from their medical training every year in ignorance of the most prevalent of all diseases? You cannot blame them, they are devoted to their teachers while in the hospitals. To them they look for guidance and inspiration. Where the teachers lead the students will follow and what the teachers ignore the students are apt to ignore also.

Space will not permit of more than a passing allusion to the effects of this upon the medical profession and through them upon the public. Much of the dental disease is due to the defective diet of the children, pre-natal and post-natal. Yet there is scarcely an artificial food upon the market which does not receive abundant recommendation from 
medical men. The medical practitioner is the confidential adviser of the mother and her offspring. The dental surgeon is helpless to prevent mischief. Only when the mischief is done is the patient handed over to him. Ten years have passed away since the British Dental Association published statistics which proved that 85 per cent. of the schoolchildren in the United Kingdom have defective teeth. When will the metical profession of this country help them to find a remedy? Our continental brethren have since examined their own chillren and fint the same defects. In Germany already remedial measures are being taken. More than ten years ago the British Dental Association placed before the medical profession facts to prove that our soldiers' and sailors' teeth required urgent attention. Yet it needed the rejection from active service and the return home of 3000 men from defective teeth alone during the late war before dental surgeons were appointed to remedy such defects in the army. The men of our navy-the finest service in the world-are in a worse plight than the army-nothing but the removal of teeth by way of treatment. Surely this is sufficient evidence of the indifference of the medical profession to dental diseases. It cannot long continue ; there are forces outside the medical profession which are making themselves felt and the greatest among them will be the opinion of the public. The remedy is as simple as the effects will be far reaching. In all final examinations throughout the kingdom let it be known that in future an occasional question will be put on the causation, effects, and treatment of dental caries. In ten years' time the 13,000 general practitioners who have registered wil be well aware of the prevalence of dental disease, which, if they cannot cure, they will do much to prevent. Such a question will be no great burden and I confidently appeal to the examiners on behalf of the British public.

Railway Approach, London Bridge, S.E.

\section{A CASE OF ULCERATIVE COLITIS WITH MULTIPLE PERFORATIONS.}

\section{By A. Garrick Wilson, B.A., M.B. Cantab., F.R.C.S. ENG., \\ LATE SLRGICAL REGIS'TAR AT ST. MARY'S HOSPITAL, LONDON.}

HAVING seen in a recent number of Trre LANCET ${ }^{1}$ some cases of ulcerative colitis I consequently thought it worth while to put on record a case which I had under my care a short time ago. The following are the notes. The patient, a male, aged 51 years, was seen for abdominal pain and diarrhœea. He had been fairly healthy until two years ago when he began to have intermittent diarrhœe with abdominal pain and occasional attacks of vomiting. A year ago he lost his wife and this being followed by other family troubles made him very depressed and from this time the symptoms had been worse He had been losing flesh rapidly for the last two years. He was not very clear as to the condition of the bowels previous to the onset of these symptoms, but as far as he could remember he was generally constipated and had occasional attacks of diarrhœea. He had never been out of Yorkshire. He had been accustomed to take only a small quantity of alcohol daily. He had never had syphilis and there were no signs of the disease. He was in a state of marked mental depression, was extremely anæmic (the red cells were $3,000,000$ per cubic millimetre), very much wasted, and his face was sallow and drawn as if in constant pain. The pulse was 100 and very feeble. The tongue was dry, brown, and furred. His appetite was very poor, and only with difficulty conld he be induced to take small quantities of milk, custard, arrowroot, cocoa, and eggs. The temperature was always subnormal, varying from $97^{\circ}$ to $98^{\circ} \mathrm{F}$

The patient complained of constant and severe pain in the lower part of the abdomen. This pain he described as passing round to the sacrum. Later in the course of the illness he also had pain in the epigastric region. Marked tenderness on pressure was present in the right and. left iliac fossæ, but it was much worse on the left side. The abdomen felt doughy; it was not distended at first but just before death it became very much distended. There were no typhoid spots. On examination of the rectum a few

1 TAE LANCET, March 12th, 1904, p. 721. internal piles were felt, while higher up the rectal wall was felt to be covered with numerons deep ulcers, between which the remaining mucons membrane seemed to project in a polypoidal manner. The rectal wall felt generally thickened and quite stiff. No mass of growth conld be felt either in the abdomen or per rectum.

The motions were very frequent at first. On an average there were about ten daily but under treatment I was able to reduce these to five a day. They were passed without pain or straining and often into the bed without the knowledge of the patient, as although there was no apparent loss of power of the sphincter, yet he had no control over defecation. The motions were small, always liquid, dark in colour, and very foul; there were only a few small pellets of frcal matter and no pellets of mucus, nor was there much mucus present, the motion consisting almost entirely of dark blood intimately mixed with it. There was no pus present. 'The urine had a specific gravity of 1010. There was no albumin or sugar. Widal's reaction was negative. Fxamination of the fæces for organisms showed the bacillus coli communis and some other large bacteria.

Salol was given in ten-grain doses three times a day as an internal antiseptic and to some extent it controlled the foul smell of the motions. Hamamelis and other internal astringents were also tried. Opium was given in various forms with large doses of carbonate of bismuth and later strychnine by the mouth and hypodermically. Brandy also was given in large doses. An enema of one pint of warm water with one drachm of tincture of opium was given twice a day from a donche can followed by an enema of ten grains of nitrate of silver to half a pint of warm water. The enema was given with a long soft rectal tube with the patient lying on his back, as he was not strong enough to remain in the knee-elbow position for long. It did not as a rule cause much pain, but it was not retained more than a few minutes. Unfortunately, it seemed to produce a feeling of sickness and as vomiting became severe and continuous the enemata were discontinued on the ninth day. Two davs later the plain water enema was again given until two days before death as it cansed a reduction in the daily number of motions. It is to be regretted that the enemata of nitrate of silver had to be discontinued as they certainly did good. A right-sided colotomy was suggested when I first saw the patient but he seemed too weak to stand it.

The patient gradually got weaker and unable to take any form of nourishment. On the dav preceding death the abdominal pain increased and the abdomen became enormously distended and tympanitic. Death came very suddenIy 15 dars after I first saw the patient.

A post-mortem examination was made on the day after death. The body was extremely emaciated. On opening the chest the lungs were found very much adherent on both sides and the pleura was greatly thickened; there were signs of old tuberculosis at both apices. The heart was small and the muscle flabby. On opening the peritoneal cavity a large amount of liquid fæcal matter escaped from the regions of the pelvis and flanks and along the line of the transverse colon. On washing this away it was found to be escaping from a large number, about ten or more small prrforations in the large intestine. The large intestine was everywhere adherent to the omentum and other structures. It was much shrunk in size and there was a good deal of fat adherent to it along the lines of the longitudinal bands. Between the longitudinal bands the intestinal wall was very thin indeed and appeared to consist of very little but the serous membrane. The colon was very friable and tore in several places on attempting removal. On opening the bowel and washing it free from blood and mucus it was found that the mucous surface presented very numerous serpiginous ulcers; in fact, there was very little mucous membrane and it appeared as islets among the ulcers. These islets of mucons membrane were swollen and congested and were studded with small pedunculated papillomatous growths. There were comparatively few nlcers in the creum and ascending colon but they increased in number as one followed the large bowel downwards and were very numerous in the rectum, the walls of which were in addition much thickened and infiltrated. The ulcers had undermined edges, they were rarely circular, but seemed to run together. They appeared deeper than they really were owing to the thickened cedematous condition of the remaining mu nous membrane. The base of the ulcer was generally 